\title{
Os Odontoideuma Bağlı Myelopati
}

\author{
Myelopathy Secondary to Os Odontoideum
}

\section{Erdal KOMUT ${ }^{1}$, Turgut KÜLTÜR ${ }^{2}$}

${ }^{1}$ Kazan Hamdi Eriş Devlet Hastanesi, Radyoloji Bölümü, ANKARA

${ }^{2}$ Kazan Hamdi Eriş Devlet Hastanesi, Fizik Tedavi ve Rehabilitasyon Bölümü, ANKARA

\begin{abstract}
ÖZET
Os odontoideum s1k görülmeyen bir kranioservikal bileşke anomalisi olup aksis korpusu ile devamlılığı olmayan düzgün sınırlı ossikülumun normal odontoid proçesin yerini almasıyla karakterizedir. Konjenital ve akkiz nedenlerle ortaya çıkabilen bu durum myelopati ve atlantoaksiyel instabilite nedeni olabilir. Burada servikal myelopati ile semptomatik olan os odontoideum vakası literatür eşliğinde tartışılarak sunulmuştur.

Elli yaşında kadın hasta bir aydır devam eden kollarda ağrı, uyuşma şikayet ile başvurdu. Ağız açık çekilen lateral ve ön-arka servikal direkt grafilerde os odontoideum açısından şüphe uyandıran görünüm izlenmiş ve prekontrast ve postkontrast aksiyel, saggital manyetik rezonans görüntüleme (MRG) yapılmıştır. Servikal bölgede spinal korda bası ve kordda myelopatik sinyal değişikliği izlenmiştir.

Os odontoideum atlantoaksiyel instabilite ve spinal kord kompreyonuna neden olabilir. Çoğunlukla asemptomatik olmakla birlikte direkt grafilerde atipik kranioservikal bileşke bulguları olan hastalarda kemik konfigürasyon anomalileri bilgisayarlı tomografi ile gösterilebilir. Ancak bu hastalarda myelopati açısından farkındalık oluşmalı ve radyolojik algoritmaya MRG dahil edilmelidir. Böylelikle bu olgularda akut veya kronik myelopatik bulgular erkenden tanınıp tedavi edilebilir.
\end{abstract}

Anahtar Kelimeler: Myelopati, Odontoid, Kranioservikal

\section{GíRIŞ}

Os odontoideum, düzgün kortikal kenarl1, atlasın anterior arkının arkasında yerleşen, hipoplastik odontoid prosesten ayrı, oval veya yuvarlak kemik parçasıdır $(1,2)$. Odontoid proses ile ilgili literaturde tanımlanan konjenital anomaliler aplazi, hipoplazi, duplikasyon, kondilikus tertius, os terminale (os avis)

\begin{abstract}
Os odontoideum is an infrequently seen craniocervical junction anomaly and it is characterized by a regular bordered ossiculum discontinuous with axis corpus displacing a normal odontoid process. This disorder may be congenital or acquired and can cause myelopathy and atlantoaxial instability. A case of os odontoideum symptomatic with cervical myelopathy is presented here with literatüre.
\end{abstract}

A 50 years old female patient applied with complaints of pain and numbness in both arms for 1 month. At the lateral and anterior posterior cervical X-rays which were taken mouth open position raised the suspicion of os odontoideum and precontrast and postcontrast axial, sagittal magnetic resonans (MRG) examination was done. Spinal cord compression and myelopathy signal change of the cord at cervical region was identified.

Os odontoideum may cause atlantoaxial instability and spinal cord compression. While being mostly asymptomatic in patients with direct $\mathrm{x}$ rays of atypic craniocervical junction signs bone configuration anomalies can be demonstrated by computerized tomography. But awareness for myelopathy should occur in these patients and MRG must be included in radiologic algorythm. So acute and chronic myelopathy signs can be detected and treated soon in these cases.

Keywords: Myelopathy, odontoid, craniocervical

ve os odontoideum'dur. Bunlardan en s1k izleneni os odontoideum'dur.

İlk defa Giacomini tarafindan 1866 'da tanımlanan os odontoideum travmatik veya konjenital etyolojik faktörler ile ortaya çıkabilmektedir (3). Ancak etyolojisi hakkında halen kesin deliller mevcut değildir $(4,5)$. Literatürde bu olguların Down Sendromu, Klippel-Feil Sendromu ve multipl epifizyal displazi ile 
birlikte olabileceği bildirilmiş olup os odontoideumun kompleks embriyolojik gelişimi konjenital nedenlerle birlikte olabileceğini düşündürebilir (6-7-8). Ancak nedeni travma veya konjenital de olsa os odontoideum olgularının atlantoaksiyel instabilite ve spinal kord kompresyonu açısından risk taşıdığı bilinmelidir. Os odonteideum olguları semptomatik olmazlarsa genellikle insidental olarak saptanırlar. $\mathrm{Bu}$ olguda servikal myelopati ile komplike olan bir os odontoideum olgusunu literatür eşliğinde tartışarak sunmayı amaçlanmıştır.

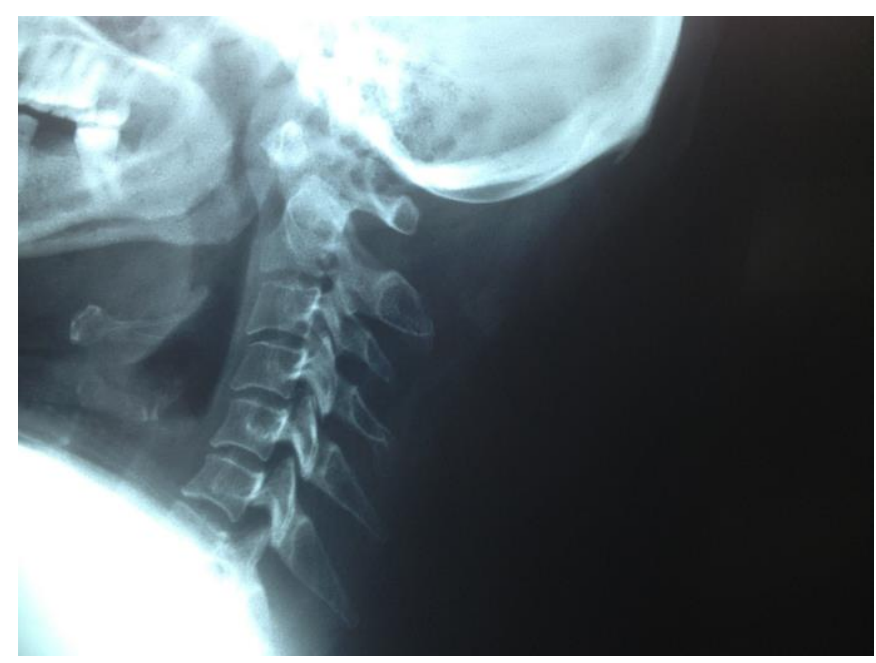

Resim 1. Fleksiyonda lateral servikal grafide dens aksis düzeyinde düzensizlik ve os odontoideuma ait görünüm

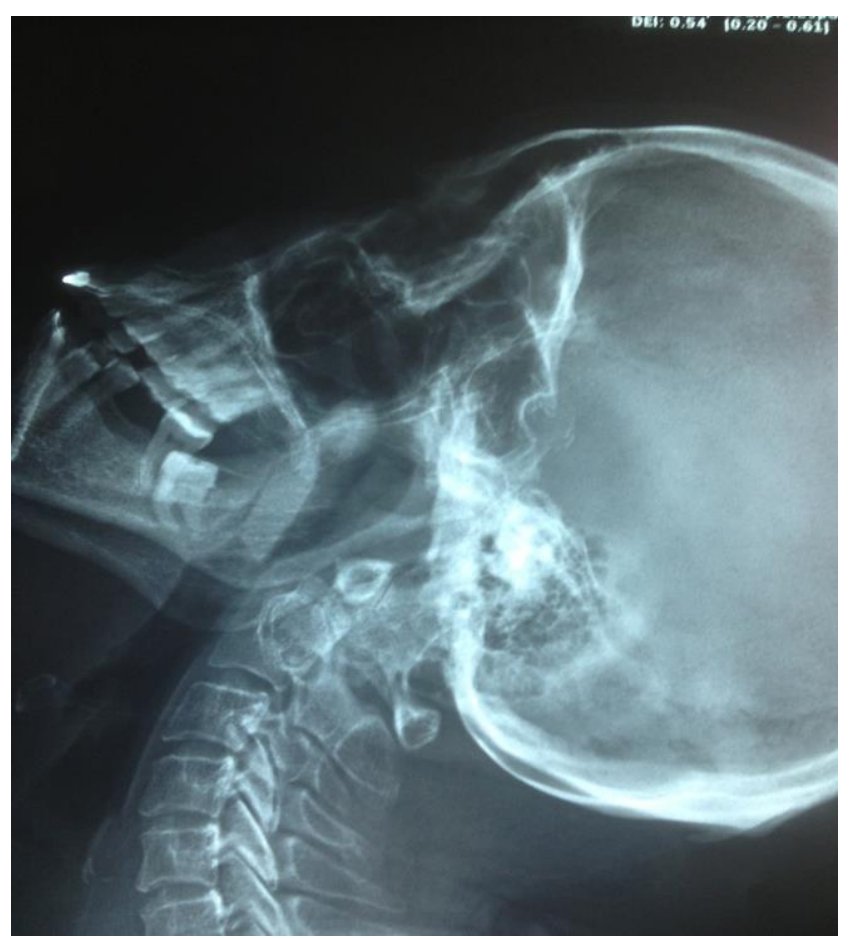

Resim 2. Ekstansiyonda lateral grafi
50 yaşında kadın hasta yaklaşık bir aydır devam eden her iki üst ekstremitede ağrı ve uyuşma şikayeti ile başvurdu. Hastanın travma veya geçirilmiş ameliyat öyküsü yoktu. Hastanın lateral fleksiyon ve ekstansiyon servikal grafilerinde C1 vertebra anterior arkusunun posterior komşuluğunda, dens aksis ile bağlantısı bulunmayan kemik yapı izlendi (Resim 1,2). 
Hastanın servikal spinal MRG incelemesinde; C2 vertebra odontoid proçesi süperior kesiminde, klivus inferiorunda, tüm sekanslarda kemik ile izointens izlenen os odontoideum ile uyumlu görünüm mevcuttu. Kaudalde izlenen odontoid proçese ait parça ise superiorda daha belirgin olmak üzere hipertrofik görünümdeydi ve posterior kesimde spinal kanala doğru uzanmaktaydı. $\mathrm{Bu}$ düzeyde posterior longitudinal ligament gergin ve posteriora doğru itilmişti. Spinal kanal odontoid proçes düzeyinde belirgin daralmıştı ve spinal kord bu kesimde basılıydı. Spinal kordun içerisinde bu düzeyde T1A serilerde hafif hipointens, T2A serilerde hiperintens alan myelopati ile uyumlu olarak değerlendirildi (Resim 3, 4, 5). İntravenöz kontrast madde enjeksiyonu sonrasında bu düzeyde patolojik kontrastlanma izlenmedi. Ayrıca servikal disklerde dejenerasyona sekonder sinyal kaybının eşlik ettiği servikal diskopatiler mevcuttu.

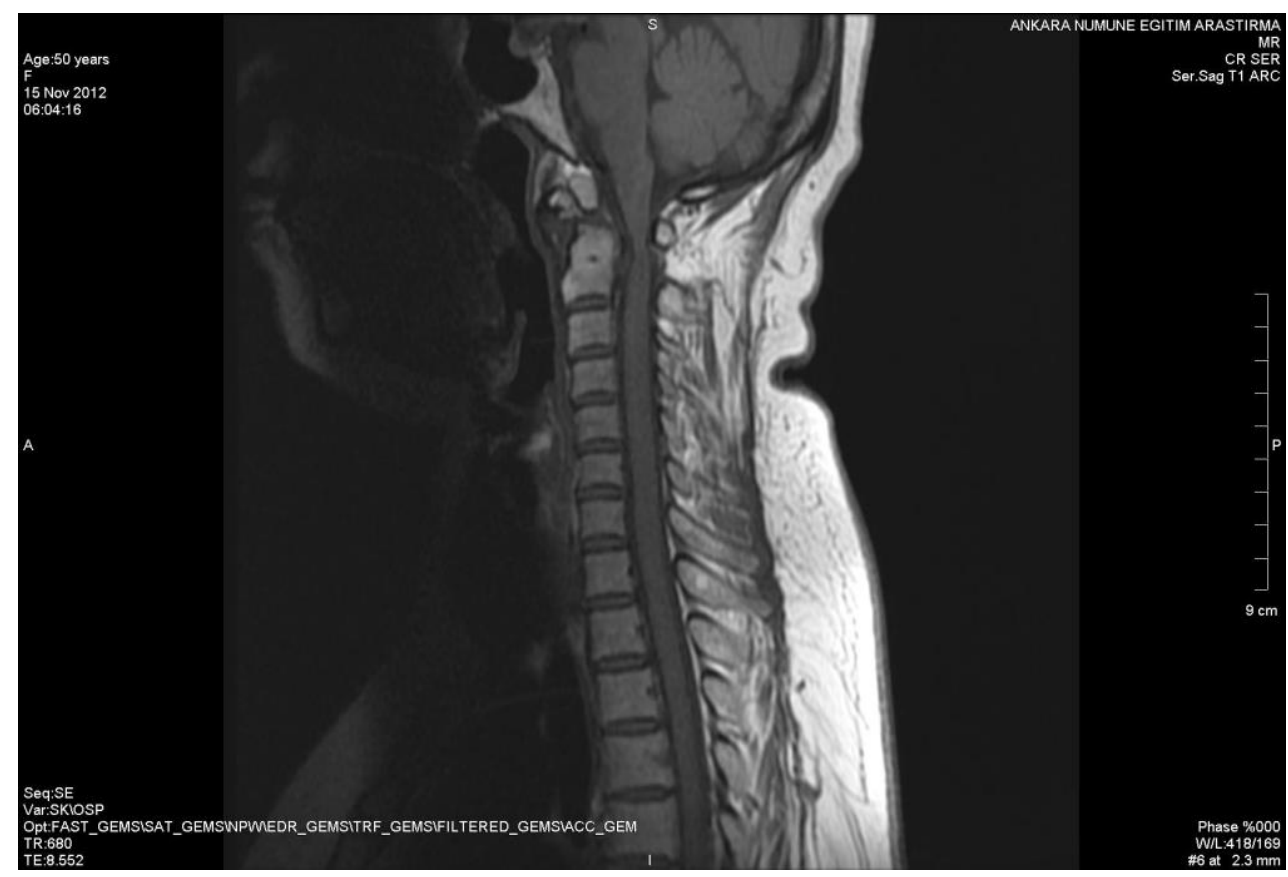

Resim 3. T1A saggital kesitlerde os odontoideum ve foramen magnumda darlık

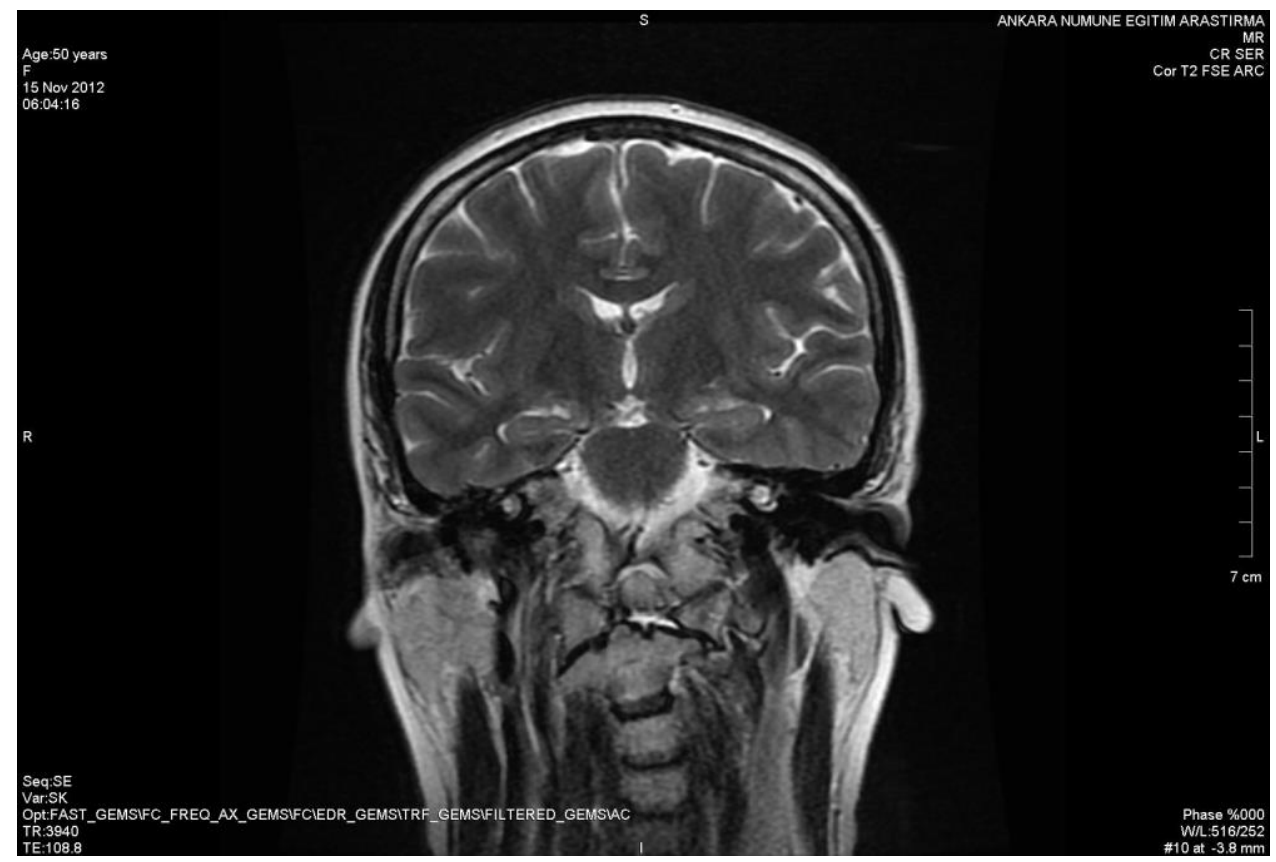


Resim 4. T2A koronal kesitlerde os odontoideum

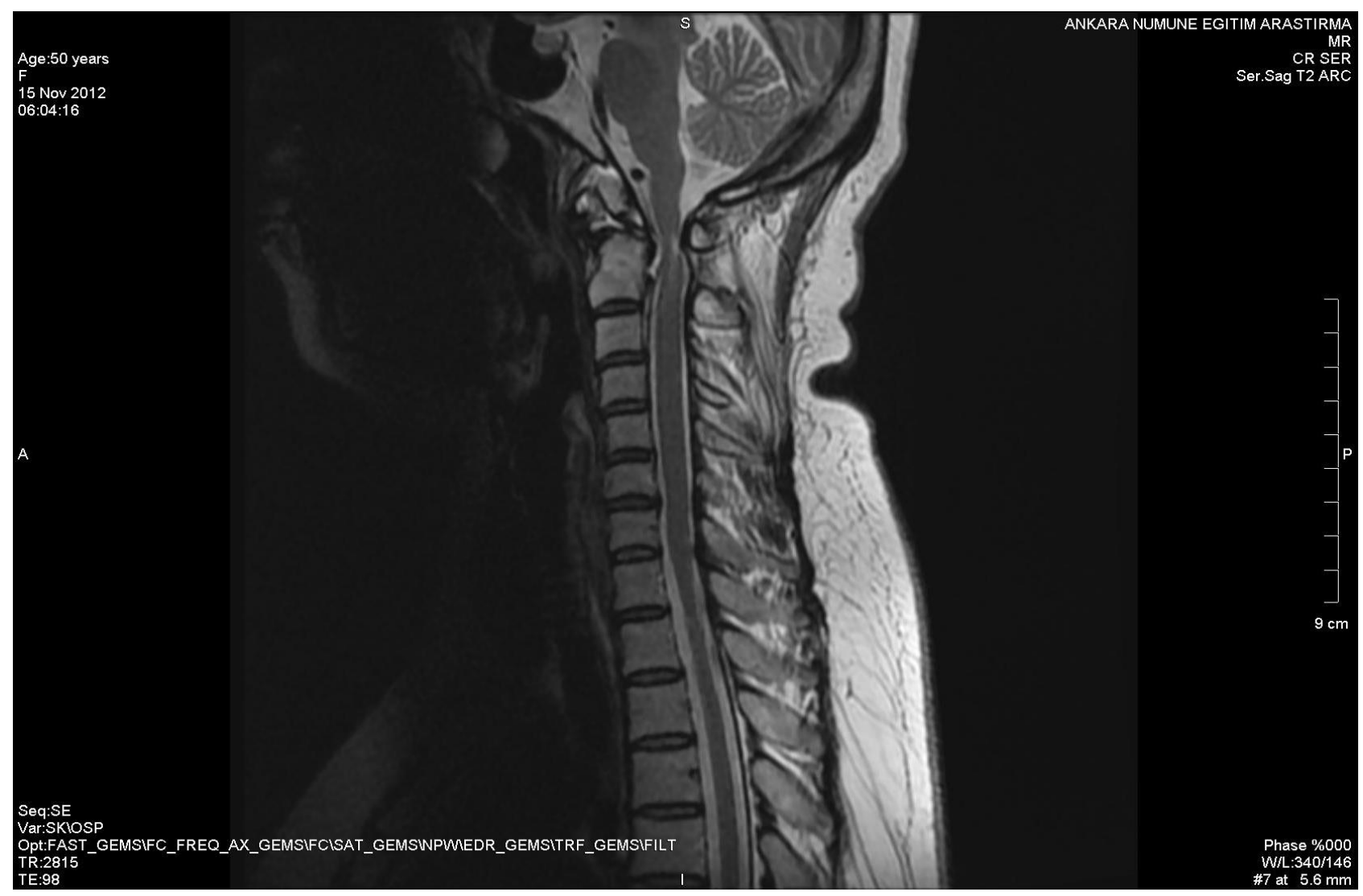

Resim 5. T2A saggital kesitlerde servikal myelopatiye ait hiperintensite

\section{TARTIŞMA}

Os odontoideum s1k görülmeyen bir kranioservikal bileşke anomalisi olup aksis korpusu ile devamlılığı olmayan düzgün sınırlı ossikulumun normal odontoid proçesin yerini almasıyla karakterizedir. Eğer kemik yap1 odontoid proçesin tepe düzeyinde yerleşimli ise ortotopik, eğer kemik yapı oksiput tabanına yakın yerleşimli ise distopik olarak sınıflandırılır. Atlantoaksiyel instabilite ve spinal kanal kompresyonuna zemin hazırlayan bir vertebral anomalidir. Bu olgularda her iki tipte de atlantoaksiyel instabilite ve spinal kord kompresyonu açısından risk olduğu bilinmelidir. Os odontoideum olguları semptomatik olmazlarsa genellikle travma sonrası yapılan incelemelerde insidental olarak saptanırlar. Radyografilerde 5 yaş altında tanının konulması için fleksiyon ve ekstansiyon grafileri ile odontoid proçesin C2 korpusu komşuluğunda hipermobilitesinin gösterilmesi gereklidir. Yetişkinde ise C2 korpusu ile os odontoideum arasında geniş ve lusent defekt görülür. $\mathrm{Bu}$ hastalarda bilgisayarlı tomografi bu düzeylerdeki eklem ilişkileri ve kemik yapıya ait patolojileri oldukça iyi karakterize edebilir. Ancak manyetik rezonans görüntülemenin spinal kord hasarını göstermedeki yeri son derece önemlidir. Travmatik veya konjenital nedenlerle ortaya çıkabilen bu durumun persistan ossikulum terminale, iyileşmemiş odontoid fraktürleri, nörosantral synkondrosis ve odontoid proçesin gerçek hipoplazisi gibi durumlarla ayırıcı tanısının yapılması gereklidir (9). Bizim olgumuzda travmatik öykü olmaması konjenital nedenleri akla getirmiştir. Fielding ve Griffin'e göre odontoidin kaynamamasının nedeni atlantoaksiyel stabilitenin sağlanmasında önemi olan alar ligamentlerin çekmesine bağlı olarak densin kan akışının bozulmasıdır (10). Ayrıca akut servikal spinal 
yaralanması olan hastalarda da os odontoideumun dens kırı ğından ayırt edilmesi gerekir. Dens kırıklarında; köşeler irreguler ve korteksi duzensizdir. Os odontoideumun farkı düzgün kenarlı, oval ya da yuvarlak, korteksi korunmuş ve köşeleri nispeten sklerotik olmasıdır (11). $\mathrm{Bu}$ bulgular bilgisayarlı tomografi ile daha iyi gösterilebilir.

Sonuç olarak; servikal direkt grafilerinde atlantoaksiyel ve kranioservikal bileşkede atipik görünüm saptanan semptomatik hastalarda bilgisayarlı tomografi bu düzeylerdeki eklem ilişkileri ve kemik yapıya ait bulguları oldukça iyi karakterize etmesine karşın MRG'nin bu hastalarda spinal kord patolojilerinin tanısındaki yeri son derece önemlidir. Os odontoideum atlantoaksiyel instabilite ve spinal kord kompresyonuna neden olabildiği için asemptomatik de olsa direkt grafide insidental olarak tanı alan olgulara mutlaka kranioservikal bileşkeye yönelik MRG incelemesi yapılması gereklidir.

\section{KAYNAKLAR}

1 Kaya AR, Turkmenoglu O, Cavusoglu H, Kahyaoglu O, Aydin Y. Os Odontoideum: A case report. Turkish Neurosurgery. 2005; 15(3): 157-61.

2 Bahadir C, Yaman V, Taraktas A. Os odontoideum kaynakli servikal myelopati: Olgu sunumu. Turk J Rheumatol. 2009; 24: 53-5.
3 Schuler TC, Kurz L, Thompson E, Hensinger RN. Natural history of os odontoideum. J Paediatr Orthop. 1991; 11: 222-5.

4 Brecknell JE, Malham GM. Os odontoideum: report of three cases. J Clin Neurosci. 2008; 15(3): 295301.

5 Mark N. Hadley, Neurosurgery, 2002; suppl. 50(3): 148-55.

6 Pueschel SM, Scola FH, Tupper TB, Pezzullo JC. Skeletal anomalies of the upper cervikal spine in children with down syndrome. J Pediatr Orthop. 1990; 10: 607-11.

7 Morgan MK, Onofrio BM, Bender CE. Familial os odontoideum. J Neurosurg. 1989; 70: 636-8.

8 Kirlew KA, Hathout GM, Reiter SD, Gold RH. Os odontoideum in identical twins: Perspectives in etiology. Skeletal Radiol. 1993; 22: 525-7.

9 Smoker WR. Craniovertebral junction: normal anatomy, craniometry, and congenital anomalies. Radiographics. 1994; 14(2): 255-77.

10 Fielding W, Griffin PP. Os odontoideum: An aquired lesion. J. Bone Joint Surg. 1974; 56: 187.

11 Cengiz Bahadır, Vildan Yaman, Aslıhan Taraktaş. Cervical Myelopathy Caused by Os Odonteideum: Case Report Turk J Rheumatol. 2009; 24: 53-5. 